\title{
Analysis of progress and challenges for various patterns of c-MET-targeted molecular imaging: a systematic review

Zhaoguo Han ${ }^{1,2+}$, Yongyi Wu ${ }^{1,2+}$, Kai Wang ${ }^{1,2}$, Yadi Xiao ${ }^{1,2}$, Zhen Cheng ${ }^{3^{*}}$, Xilin Sun ${ }^{1,2,3^{*}}$ and Baozhong Shen ${ }^{1,2^{*}}$ (D)

\begin{abstract}
Background: Mesenchymal-epithelial transition factor also named c-MET is a receptor tyrosine kinase for the hepatocyte growth factor that plays a pivotal role in tumorigenesis. c-MET-targeted therapies have been tested in preclinical models and patients, with significant benefits for cancer treatment. In recent years, many studies have shown that the expression level and activation status of c-MET are closely correlated to c-MET-targeted therapy response and clinical prognosis, thus highlighting the importance of evaluating the c-MET status during and prior to targeted therapy. Molecular imaging allows the monitoring of abnormal alterations of c-MET in real time and in vivo.

Results: In this review, we initially summarize the recent advances in c-MET-targeted molecular imaging, with a special focus on the development of imaging agents ranging in size from monoclonal antibody to small molecule. The aim of this review is to report the preclinical results and clinical application of all molecular imaging studies completed until now for in vivo detection of c-MET in cancer, in order to be beneficial to development of molecular probe and the combination of molecular imaging technologies for in vivo evaluation of c-MET. Various molecular probe targeted to c-MET possesses distinctive advantages and disadvantages. For example, antibody-based probes have high binding affinity but with long metabolic cycle as well as remarkable immunogenicity.

Conclusions: Although studies for c-MET-targeted molecular imaging have made many important advances, most of imaging agents specifically target to extracellular area of c-MET receptor; however, it is difficult to reflect entirely activation of c-MET. Therefore, small molecule probes based on tyrosine kinase inhibitors, which could target to intracellular area of c-MET without any immunogenicity, should be paid more attention.
\end{abstract}

Keywords: Molecular imaging, Malignancy, c-MET, Targeted molecular probe, Effectiveness evaluation

\section{Background}

Clinical relevance of the HGF/c-MET signaling pathway: structure, function, and dysregulation

Mesenchymal-epithelial transition factor (c-MET) is a receptor tyrosine kinase (RTK) naturally activated by the binding of hepatocyte growth factor (HGF), and then regulates many essential cellular processes including cell

\footnotetext{
* Correspondence: zcheng@stanford.edu; sunxilin@aliyun.com; shenbz@ems.hrbmu.edu.cn

${ }^{\dagger}$ Equal contributors

${ }^{3}$ Molecular Imaging Program at Stanford (MIPS), Department of Radiology, Stanford University School of Medicine, Lucas Center, Room P089, 1201 Welch Rd, Stanford, CA 94305-5484, USA

${ }^{1}$ Molecular Imaging Research Center, Harbin Medical University, 766Xiangan N street, Songbei District, Harbin, Heilongjiang 150028, China

Full list of author information is available at the end of the article
}

proliferation, motility, invasion, angiogenesis, and apoptosis. The c-MET oncogene is located on chromosome 7q21-31 and was initially identified in an immortalized osteosarcoma cell line by Cooper et al. in the1980s [1]. The c-MET receptor is located in the cell surface and is expressed in epithelial cells of many organs including the liver during both embryogenesis and adulthood [2].

The mature form of the c-MET receptor is a disulfidelinked heterodimer consisting of a $50-\mathrm{kDa}$ extracellular $\alpha$-chain and a transmembrane $140-\mathrm{kDa} \beta$-chain. Both the $\alpha$ chain and the first 212 residues of the $\beta$ chain constitute the Sema domain, which has an HGF-binding site in the extracellular region [3].

HGF [4, 5], also known as scatter factor [6], is the only endogenous ligand for c-MET [7]. HGF is a $90-\mathrm{kD}$ 
multidomain glycoprotein that is similar to plasminogen, a circulating proenzyme. HGF is cleaved by proteases to form, similarly to its receptor, $\alpha / \beta$ heterodimers linked by a disulfide bond, thereby converting it into the active form [8]. The $\mathrm{NH}_{2}$-terminal portion of the HGF $\alpha$ chain contains the high affinity c-MET binding domain, and the $\beta$ chain is responsible for activating c-MET receptor via a direct interaction.

After HGF-binding, the c-MET receptor undergoes homodimerization and phosphorylation at tyrosines 1234 and 1235 and subsequently at tyrosines 1349 and 1356 in the carboxy-terminal tail [9]. After phosphorylation, these tyrosines recruit GRB2 (adaptor protein growth factor receptor bound protein 2) [10], SHC (Srchomology-2-containing) [11] and CRK (v-crk sarcoma virus CT10 oncogene homolog), CRKL [12, 13], PI3K (the effector molecule phosphatidylinositol 3-kinase), PLCY (phospholipase $\mathrm{C} \gamma$ ), and a series of signaling effectors that have been described in detail in previous reviews [14-17]. Similarly to many RTKs, components of the c-MET downstream signaling pathways such as MAPK will translocate into the nucleus and bind transcription factors to regulate the transcription of specific genes involved in a variety of cellular processes including cell proliferation, motility, and cell cycle progression $[10,18]$. Other major downstream axes of c-MET signaling include the PI3K/Akt and STAT/JNK signaling axes, responsible for cell survival and transformation, respectively $[13,19]$.

It is known that dysregulation of many RTKs, including c-MET, contributes to tumorigenesis [20]. Indeed, c-MET is activated in a variety of cancers, such as renal, ovarian, and lung. $[8,21]$. Aberrant activation of c-MET results in proliferation, invasion, angiogenesis, and inhibition of apoptosis [19, 22, 23]. Conversely, downregulation of MET expression in tumor cells can lower their tumorigenic potential [24]. Studies indicated that c-MET in cancer is activated through both ligand-dependent autocrine or paracrine mechanisms and ligand-independent mechanisms including gene amplification, gene translocation, activating mutations, or transcriptional upregulation of the c-MET protein [25, 26]. Furthermore, in some studies, a synergistic effect for phosphorylation between c-MET and epidermal growth factor receptor (EGFR), HER2, HER3, RAS, RON, or PDGFR was found in some cancer cells or transfected cancer cells, and these studies might have important significance for combination therapy in many cancers [27-32].

c-MET is an attractive drug target in cancer therapy, and various targeted drugs have been used in multiple clinical trials as cancer therapeutic agents [33]. Furthermore, combined therapy targeted to c-MET and EGFR (onartuzumab + erlotinib) has significantly reduced resistance to treatment in preclinical studies when compared to erlotinib alone, but failed to get consistent result in a clinical trial
[34-36]. Maybe more comprehensive clinical setting needs to be performed to confirm the prospective viewpoint.

\section{Molecular imaging of c-MET}

As c-MET is an active participant in tumorigenesis and the malignant progress, the assessment of c-MET activation status in real time could be valuable for diagnosis and monitoring of responses to targeted therapies in cancer in the future. While c-MET detection by immunohistochemistry or fluorescent in situ hybridization (FISH) is currently the standard diagnostic procedure, these methods require repeated biopsies that can be painful for the patient. Thus, the development of more effective noninvasive detection methods for accessing cMET expression and activation is needed.

Molecular imaging is a noninvasive method that can provide accurate information in vivo and in real time, and its application for detecting c-MET activation could represent a breakthrough in cancer diagnosis. Various c-METtargeted tracers have been developed based on multiple molecular modalities, such as antibody, peptide, small protein, genetically encoded protein, and small molecule tyrosine kinase inhibitor (TKI). These tracers also have been further evaluated in preclinical studies or clinical setting. Recent studies acquired significant progress toward the development of molecular imaging probes for monitoring c-MET activation, but the imaging performance of these probes remains a critical issue. Here, we review and discuss these studies (Fig. 1, Table 1).

\section{Review}

\section{Various patterns of molecular probes targeted to c-MET Molecular imaging agents based on the HGF ligand}

It is well established that HGF can alter the hemodynamics and metabolism of normal and malignant c-METexpressing tissues [37, 38], and it has been gradually recognized that HGF has high binding affinity and specificity to c-MET. Initial studies on targeted molecular imaging of cMET were therefore mainly based on HGF ligands. Shaharabany et al. [39] demonstrated in 2001 that hemodynamic changes induced by HGF correlated to c-MET activation in vivo. HGF was injected into xenografts in mice model, and then the mice were imaged by magnetic resonance imaging (MRI) and Doppler ultrasound. Results measured by blood oxygenation level dependent (BOLD)-MRI indicated that organs and tumors expressing c-MET levels showed more substantial alteration in blood oxygenation levels than those without c-MET expression. For instance, $60 \%$ of MRI signal alteration was detected in the liver, which has high levels of c-MET expression, whereas in the kidneys, only $30 \%$ signal alteration was detected, and no change was observed in the muscles. In mice bearing tumors derived from DA3 (murine mammary adenocarcinoma) cell line expressing high levels of c-MET, significantly higher signal intensity was 


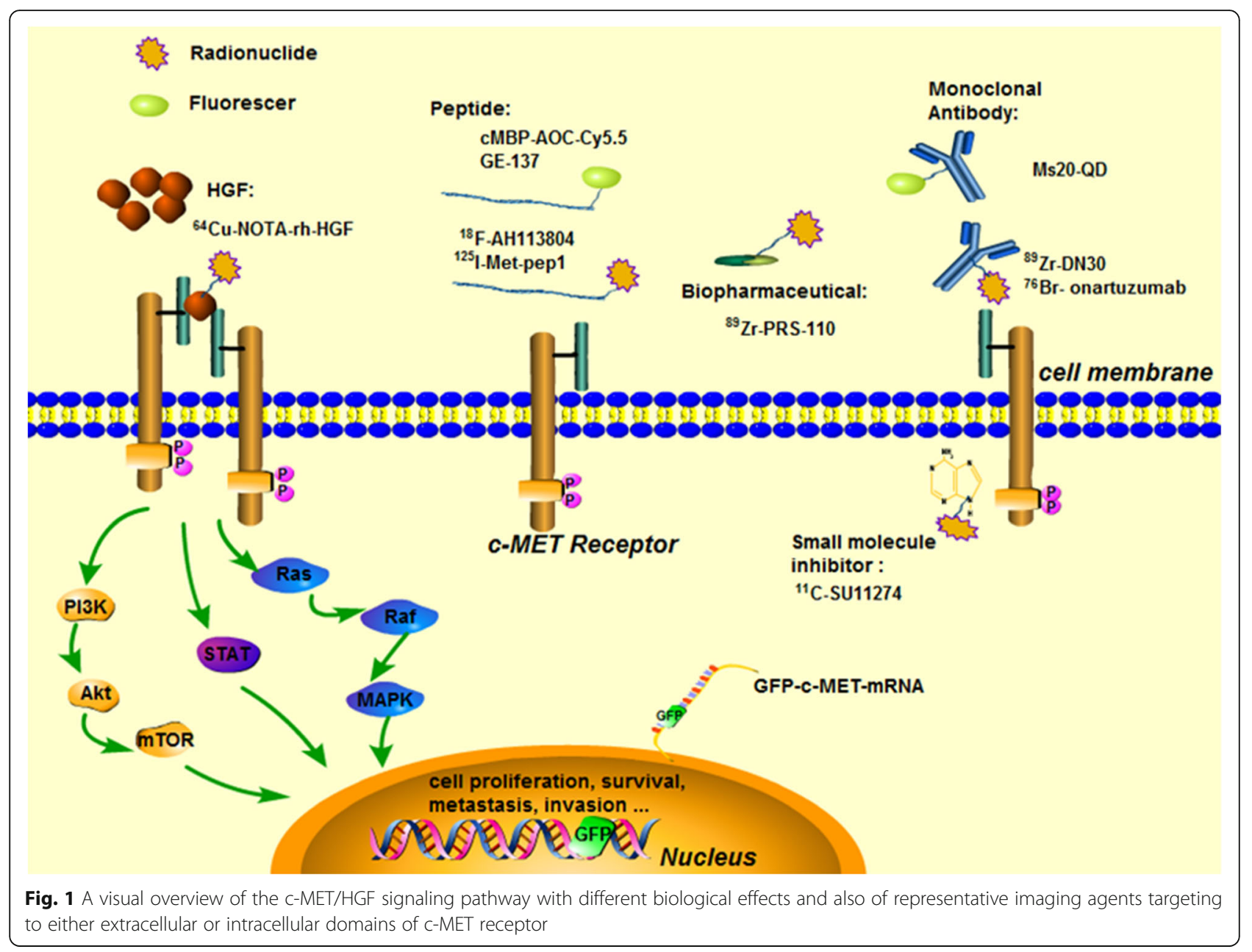

detected, and in particular within the tumors when compared to the tumor periphery. The hemodynamic impact in the liver and kidneys in these mice were similar to those measured in the mice bearing tumors with low c-MET expression described above. In this elegant study, the authors show that MRI signal alterations are not only specific to cMET activation but they are also dose dependent, as injection of HGF at 7 and $170 \mathrm{ng} / \mathrm{g}$ body weight resulted in signal alterations of 5 and 30\% respectively. Similarly, in 2006, Tsarfaty et al. imaged c-MET activation in vivo indirectly by microbubble contrast medium $(\mathrm{CM})$ ultrasound imaging after administration of HGF in murine models. Interestingly, the "newly opened" vessels (vessels that could not be detected before administration of HGF) caused by HGF treatment were mainly responsible for tumor blood volume increase [40].

More recently, in 2015, Luo et al. reported the synthesis of ${ }^{64} \mathrm{Cu}$-NOTA-rh-HGF (recombinant human hepatocyte growth factor) and evaluated its potential as a PET imaging radiotracer for c-MET-targeted molecular imaging [41]. The synthesis of ${ }^{64} \mathrm{Cu}-\mathrm{NOTA}$-rh-HGF was accomplished by conjugating concentrated rh-HGF to p-SCN-
Bn-NOTA and subsequently chelating with ${ }^{64} \mathrm{Cu}$. Flow cytometry examination in U87-MG (human glioblastoma) and MDA-MB-231(human breast cancer) cell lines, which have moderate level and low level expression of c-MET, respectively, confirmed the specific binding capacity of rh-HGF to c-MET. In vivo studies further revealed that tumor uptake of ${ }^{64} \mathrm{Cu}$-NOTA-rh-HGF was rapidly and clearly visible at $0.5 \mathrm{~h}$ post-injection (p.i.) and peaked at 9 h p.i. $(6.7 \pm 1.8 \% \mathrm{ID} / \mathrm{g})$ in U87-MG xenografts in mice; however, it was significantly lower in MDA-MB-231 xenografts in mice $(1.8 \pm 0.6 \% \mathrm{ID} / \mathrm{g}$ at $9 \mathrm{~h}$ p.i.), with consistency between PET images and biodistribution data in both models (Fig. 2). On the other hand, ${ }^{64} \mathrm{Cu}$-NOTAdnrh-HGF, which was heat denatured and hence could not bind to c-MET, had significantly lower uptake in U87-MG xenografts than ${ }^{64} \mathrm{Cu}-\mathrm{NOTA}-\mathrm{rh}-\mathrm{HGF}$, with the highest value at $1.6 \pm 0.6 \% \mathrm{ID} / \mathrm{g}$ at $15 \mathrm{~h}$ p.i. Furthermore, probe uptake in all major organs was comparable between ${ }^{64} \mathrm{Cu}$-NOTA-rh-HGF and ${ }^{64} \mathrm{Cu}-\mathrm{NOTA}-\mathrm{dnnh}-\mathrm{HGF}$, further confirming the specificity of the tracer to c-MET. The liver and kidney uptake of ${ }^{64} \mathrm{Cu}$-NOTA-dnrh-HGF were comparable to those of mice injected with ${ }^{64} \mathrm{Cu}$ - 


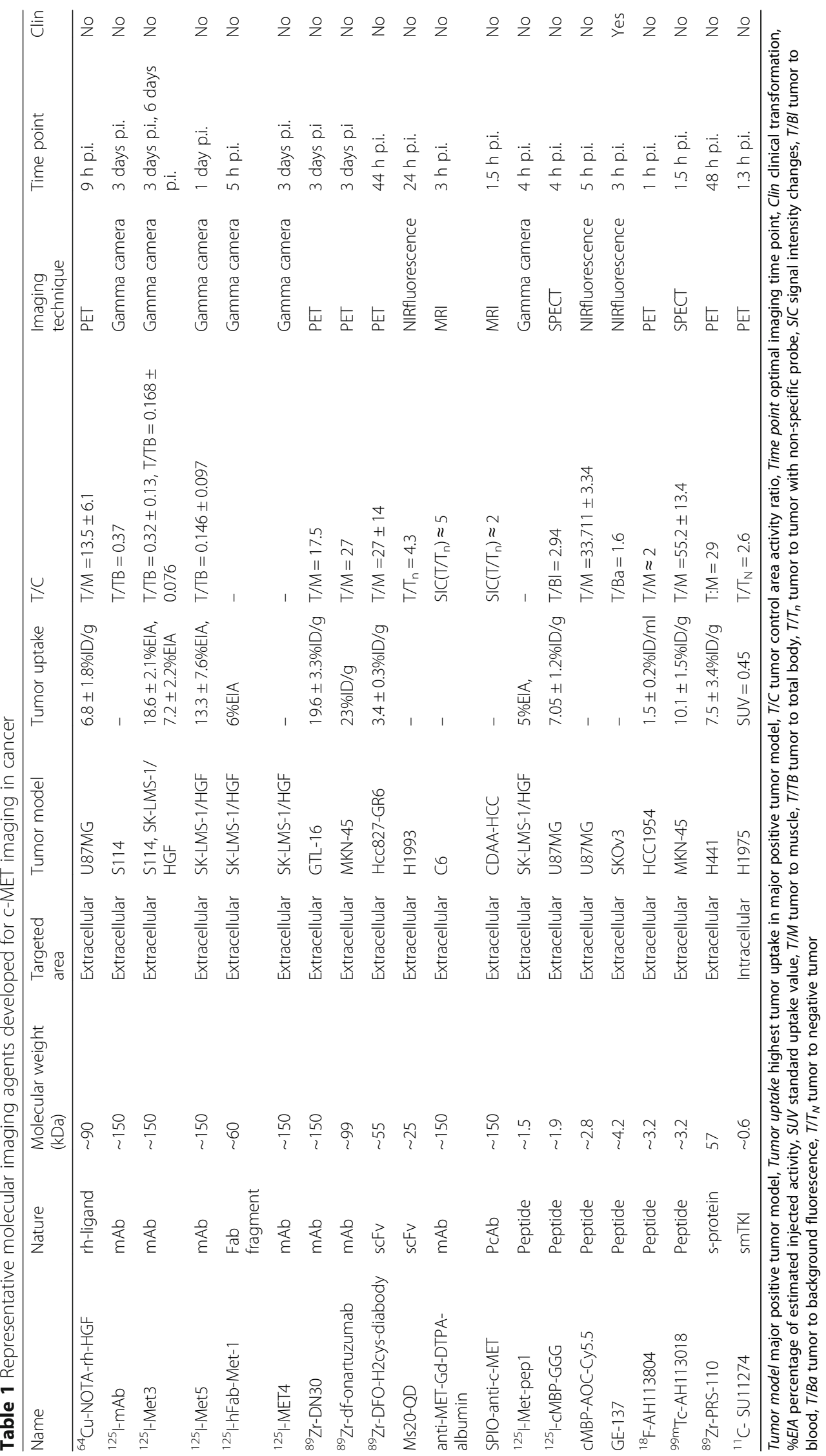




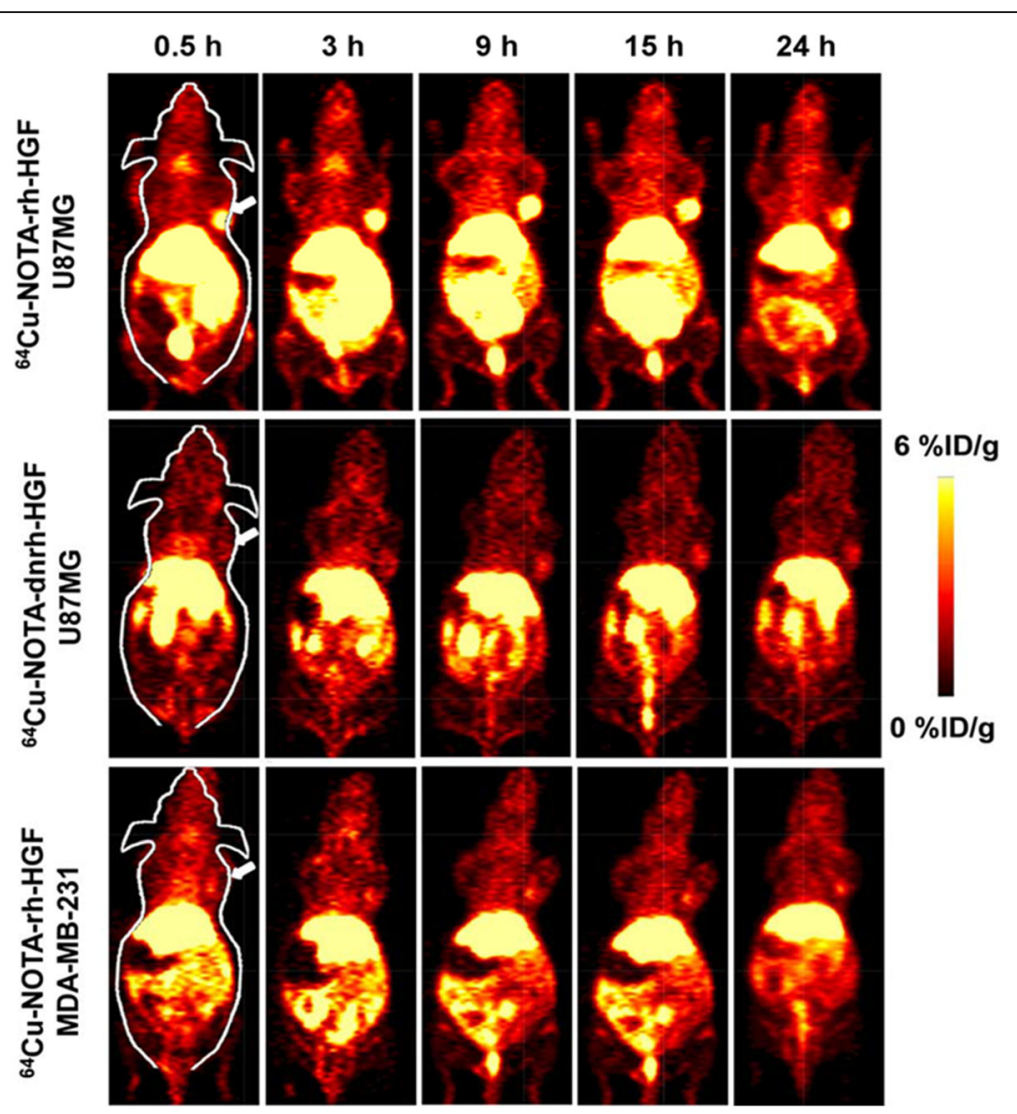

Fig. 2 Coronal micro-PET images of C-Met expression in U87-MG and MDA-MB-231 bearing mice at serial timepoint post-injection of ${ }^{64} \mathrm{Cu}-\mathrm{NOTArh}-\mathrm{HGF}$ or ${ }^{64} \mathrm{Cu}-\mathrm{NOTA}$-dnrh-HGF are shown, and tumors are indicated by arrows. With permission from reference [41]

NOTA-rh-HGF, as expected since these should be the clearance organs for a tracer of this size. With a molecular weight of $\sim 90 \mathrm{kDa}$, rh-HGF is significantly smaller than monoclonal antibodies (mAbs) (typically $150 \mathrm{kDa}$ ). Therefore, the smaller ${ }^{64} \mathrm{Cu}-\mathrm{NOTA}-\mathrm{rh}-\mathrm{HGF}$ displayed a faster circulation clearance than radiolabeled intact mAbs, which also obtained a higher optimal tumor/ muscle ratio ( $13.5 \pm 6.1$ at 9 h p.i. in U87-MG xenografts) in less than a half-life period.

These studies demonstrate that imaging agents based on the endogenous HGF ligand could be a straightforward and effective approach to image c-MET. However, while HGF displays good pharmacokinetic properties and high selectivity to c-MET, it also presents significant disadvantages. For instance, endogenous ligands will inevitably induce biological effects such as increased cell proliferation and enhanced cell survival and could also stimulate tumor growth. In addition, the endogenous ligand will theoretically preclude the preferential uptake of the radiolabeled ligand versus the unlabeled ligand in animal tumor models and therefore reduce contrast ratio of the tumor PET or SPECT images [42]. These limitations hinder the clinical translation of HGF-based molecular imaging and need be addressed in the future.

\section{Molecular imaging agents based on antibodies}

In the past two decades, several monoclonal antibodies (mAbs) against the HGF/c-MET signaling pathway including rilotumumab, ficlatuzumab, DN30, and onartuzumab, among others, have been extensively studied in preclinical and clinical trials, with promising outcomes in cancer treatment. Consequently, antibodies have also become of interest in the search for viable imaging agents for c-MET-targeted molecular imaging.

Preliminary work by Hay et al. tested a mAbs-based radiotracer mixture for molecular imaging of c-MET [43]. The radioiodinated $\mathrm{mAb}$ mixture $\left({ }^{125} \mathrm{I}-\mathrm{mAb}\right)$ consisted of anti-c-MET mAb and anti-HGF mAb. So they can target tumor cells directly and indirectly by binding to c-MET and HGF, respectively. The ${ }^{125} \mathrm{I}-\mathrm{mAb}$ mixture was synthesized with a radiolabeling efficiency of $>60$ and $>85 \%$, and the radioactivity was detected by whole body gamma camera imaging as early as $1 \mathrm{~h}$ p.i. in SK-LMS-1 (human leiomyosarcoma with high expression of c-MET) and S-114 (NIH 3T3 cells transformed with human HGF and human c-MET) murine models, whereas initial visualization of tumors in M-114 and DA3 murine models were at 1 day p.i. (M-114, NIH 3 T3 cells transformed with murine HGF and murine c-MET; DA3, mouse mammary carcinoma 
expressing murine c-MET). Quantitative ROI (region of interest) analyses indicated that tumors with autocrine for human HGF and c-MET demonstrated more rapid uptake and clearance of the ${ }^{125} \mathrm{I}-\mathrm{mAb}$ mixture than tumors expressing one or both murine homologues, reaching a mean value of tumor-to-whole body activity ratio by $>0.3$ at 1 day p.i. Generally, mice bearing "human" tumors (SKLMS-1 and S-114) display a faster uptake and a faster metabolism of tracer from body than mice bearing "murine" tumors (M-114, DA3), as shown in images (lower levels of splanchnic activity at 3 and 5 days p.i. and more conspicuous thyroid activity derived from uptake of free radioiodide released by $\mathrm{mAb}$ deiodination). This study did not however include a HGF/c-MET negative control group. In a follow-up study, Hay et al. compared two anti-c-MET mAbs, Met3 and Met5, for nuclear imaging of human and canine c-MET-expressing tumor xenografts in nude mice [44]. Met5 and Met3 were radioiodinated with ${ }^{125} \mathrm{I}$ by the same procedure described previously, with a radiolabeling efficiency of $>60$ and $>90 \%$ [43]. In qualitative terms, Met3 and Met5 had comparable results of PC-3 tumors (human prostate cancer with high expression of c-MET) and SK-LMS-1/HGF tumors in mice models with high tumor/whole body ratio. In quantitative ROI analyses, both mice models injected with ${ }^{125}$ I-Met3 exhibited the highest uptake value at the earliest imaging time point (typically 1 to $2 \mathrm{~h}$ post-injection) and declined over time, similarly to previous research [45]. However, ${ }^{125}$ I-Met5injected xenografts in mice models exhibited the highest uptake value at 1 day p.i., with respectively $13.3 \pm 7.6 \% \mathrm{EIA}$ (percentage of estimated injected activity) in SK-LMS-1/ HGF, $7.5 \pm 3.4 \%$ EIA in PC-3, and remained high until the final imaging point (5-6 days after injection). Although quantitative analysis indicated faster tumor uptake for ${ }^{125}$ I-Met3, ${ }^{125}$ I-Met5 obtained higher and more durable tumor uptake (at least 5 days). Therefore, Met 5 might be more useful for radioimmunotherapy. Inevitably, distinct thyroid activity was observed since 1 day p.i. caused by deiodination from tracers. For ${ }^{125}$ I-LF7, a negative control $\mathrm{mAb}$, the tumor uptake was $<3 \%$ EIA at any time point. Ex vivo tissue uptake measurements were however not performed in this study.

To reduce the effects of c-MET activation induced by $\mathrm{mAbs}$ or native ligands on c-MET expression in vivo, Jiao et al. assessed the feasibility of using a monovalent anti-cMET antigen-binding fragment (Fab, $\sim 60 \mathrm{kDa}$ ) as a molecular probe for targeted imaging of c-MET [46]. hFabMet-1 was selected from a large human naive Fab phagedisplay library with high specificity to c-MET but without agonist activity to HGF/c-MET signaling, as confirmed by in vitro assays. In an in vivo study, activity started to accumulate in tumor regions at $1-2 \mathrm{~h}$ after injection of ${ }^{125} \mathrm{I}$ hFab-Met-1, it was highly accumulated at 5-8 h p.i. and persisted for at least $24 \mathrm{~h}$ in SK-LMS-1/HGF bearing mice models, with a mean tumor activity of about $6 \%$ of the estimated activity administrated. Particularly high accumulation of activity was detected in the thyroid region. Although possessing smaller molecular weight and therefore faster metabolism as well as tumor uptake than the whole antibody, the Fab single fragment has a lower binding affinity than the whole antibody, as we have seen for ${ }^{125}$ I-hFab-Met-1, obtained highest tumor uptake of 6\%EIA which is lower than ${ }^{125}$ I-Met5 ( 13\%EIA).

In 2009, Knudsen et al. [47] developed a new mAb (MET4) to use as a radiotracer for c-MET-targeted molecular imaging. MET4 targets overexpressed c-MET in tumors by binding to a specific epitope located in the extracellular domain of c-MET. The radiolabeling of MET4 with ${ }^{125}$ I was accomplished by direct electrophilic radioiodination, as described in a previous study [45]. Nuclear images of c-MET-overexpressing mice tumor models injected with ${ }^{125}$ I-MET4 were qualitatively and quantitatively comparable to the best images published previously [43-45]. Moreover, biodistribution analyses revealed that MET4 is a durable antibody for in vivo applications, with an unusually long biological half-life of about $150 \mathrm{~h}$ (6.25 days) when compared to other fulllength antibodies, which have a half-life of about 2-4 days, and therefore MET4 might be a candidate agent for radioimmunotherapy.

It is widely accepted that compounds labeled with positron-emitting radionuclides for PET imaging can produce images with higher resolution and which allow a more accurate quantitative analysis [48, 49]. Currently, only two positron-emitting radionuclides offer optimal tumor/nontumor ratios for intact mAbs (i.e., over 24 days $):{ }^{89} \mathrm{Zr}\left(\mathrm{t}_{1 / 2}=78.4 \mathrm{~h}\right)$ and ${ }^{124} \mathrm{I}\left(\mathrm{t}_{1 / 2}=100.3 \mathrm{~h}\right)$. Perk et al. initially reported the radiolabeling of DN30, a mAb reactive to c-MET labeled with ${ }^{89} \mathrm{Zr}$ for assessing c-MET expression status in vivo by PET imaging [50]. The incorporation of ${ }^{89} \mathrm{Zr}$ into DN30 was accomplished through a bi-functional metal chelating moiety conjugated to the mAb (N-sucDf-DN30). The radiolabeling achieved moderate yields of $>70 \%$, radiochemical purity of $>95 \%$, and specific radioactivities ranging from 54 to $70 \mathrm{MBq} /$ mg. In biodistribution studies of xenografts in mice models, the uptake of ${ }^{89} \mathrm{Zr}-\mathrm{N}$-sucDf-DN30 ( $\left.{ }^{89} \mathrm{Zr}-\mathrm{DN} 30\right)$ in $\mathrm{FaDu}$ (human head-and-neck cancer with low c-MET expression) tumors was significantly lower than that in GTL-16 (human gastric cancer with high c-MET expression) tumors, specifically, at 3 days p.i. $7.8 \pm 1.2 \% \mathrm{ID} / \mathrm{g}$ was detected in FaDu tumors and $18.1 \pm 4.5 \% \mathrm{ID} / \mathrm{g}$ in GTL-16 tumors. Consistent with these results, the radioactivity was more pronounced in the GTL-16 tumors when compared to FaDu tumors, and it is noteworthy that GTL-16 tumors as small as $11 \mathrm{mg}$ were clearly visualized. Although sensitive for detection of small tumors, ${ }^{89} \mathrm{Zr}$-DN30 displayed relatively high uptake in the liver and spleen, 
partly due to residualization of ${ }^{89} \mathrm{Zr}$ after catabolism of the conjugate in these organs. In summary, the DN30 monoclonal antibody accurately measures c-MET expression, as confirmed by IHC, and can be used for molecular imaging in vivo.

Onartuzumab, an experimental therapeutic 1-armed monoclonal antibody, was radiolabeled with ${ }^{76} \mathrm{Br}$ or ${ }^{89} \mathrm{Zr}$ and tested as a targeted molecular imaging agent in c-MET expressing cell lines and xenografts in mice models by Jagoda et al. in 2012 [51]. ${ }^{89} \mathrm{Zr}$-desferrioxamine (df)-onartuzumab was synthesized using a df-conjugate, with yields of $>90 \%$ and specific radioactivities ranging from 0.037 to $0.185 \mathrm{MBq} / \mu \mathrm{g} .{ }^{76} \mathrm{Br}$-onartuzumab was radiolabeled directly, with low yields of $>45 \%$ and specific radioactivities of 0.118 $\pm 0.067 \mathrm{MBq} / \mu \mathrm{g}$ with high specific binding affinity for cMET. In biodistribution studies, uptake in MKN-45 (human gastric carcinoma with high c-MET expression) tumors of ${ }^{76} \mathrm{Br}$-onartuzumab was about 2-fold higher than in U87-MG tumors (moderate level c-MET expression). However for ${ }^{89} \mathrm{Zr}$ - df-onartuzumab, the uptake in the U87-MG tumors was 3-fold lower than that in the MKN-45 tumors at 5 days p.i., consistent with c-MET expression. Both ${ }^{76} \mathrm{Br}$ onartuzumab and ${ }^{89} \mathrm{Zr}$-df-onartuzumab had a similar uptake in non-target tissues in all tumor models. In blocking studies for MKN-45 xenografts, tumor uptake of ${ }^{89} \mathrm{Zr}$ - dfonartuzumab decreased approximately 3.8 -fold by plus of $10 \mathrm{nmol}$ of unlabeled onartuzumab, suggesting that competitive blocking by unlabeled onartuzumab occurred in the tumor. In summary, ${ }^{76} \mathrm{Br}$-onartuzumab showed lower retention in the tumors when compared to ${ }^{89} \mathrm{Zr}$-df-onartuzumab, with clearance similar to the radioactivity in blood. For micro-PET imaging in MKN-45 xenografts, tumors injected with ${ }^{76} \mathrm{Br}$-onartuzumab could be detected as early as $18 \mathrm{~h}$ p.i., with optimal visualization at $24 \mathrm{~h}$ p.i. However, although tumors injected with ${ }^{89} \mathrm{Zr}$-df-onartuzumab could also be visualized at $18 \mathrm{~h}$ p.i., the image quality continued to improve over the 5-day period. ${ }^{89} \mathrm{Zr}$-df-onartuzumab accumulation in the normal tissues-blood, heart, lungs, gastrointestinal tract, and muscle-decreased slowly, with reduction of $<50 \%$ from $18 \mathrm{~h}$ to 5 days, and in contrast, liver and kidney uptake increased over time, indicating hepatobiliary and renal clearance for ${ }^{89} \mathrm{Zr}$-df-onartuzumab. In addition, high bone uptake (up to $7 \% \mathrm{ID} / \mathrm{g}$ ) at 5 days p.i. was observed, due to free ${ }^{89} \mathrm{Zr}$ from the chelated tracer.

In 2014, Li et al. radiolabeled fully human single-chain variable fragments-cys-diabodies ( $\mathrm{scFv}$-cysdimmers, $\mathrm{H} 2$ ) with ${ }^{89} \mathrm{Zr}$ for immuno-PET studies in xenografts in mice models expressing c-MET [52]. The ${ }^{89} \mathrm{Zr}$-labeled $\mathrm{H} 2$ cys-diabody ( ${ }^{89} \mathrm{Zr}-\mathrm{DFO}-\mathrm{H} 2$ cys-diabody) was sitespecifically conjugated with maleimide-DFO, and prepared with labeling efficiency of $49 \%$, radiochemical purity of $95 \%$, and specific activity of $0.13 \mathrm{MBq} / \mu \mathrm{g}$. The ${ }^{89} \mathrm{Zr}$-DFO-H2 cys-diabody showed a specific uptake in Hcc827-GR6 tumors (gefitinib-resistant human non- small-cell lung cancer (NSCLC) with high c-MET expression) that was higher than the uptake in Hcc827 (human NSCLC with low c-MET expression) tumors in PET scans at both 4 and $20 \mathrm{~h}$ p.i.; high-contrast images were obtained as early as $4 \mathrm{~h}$ p.i. In ex vivo biodistribution assays, at $4 \mathrm{~h}$ after injection, Hcc827-GR6 tumors had higher uptake levels at $1.8 \pm 0.2 \% \mathrm{ID} / \mathrm{g}$ when compared to the negative control Hcc827 tumors at $0.65 \pm$ $0.15 \% \mathrm{ID} / \mathrm{g}$. High kidney uptakes observed in both biodistribution and PET images were induced by clearance of these low molecular weight cys-diabody proteins. The specificity of anti-c-MET targeting by the $\mathrm{H} 2$ minibody (antibody fragment reformatted from $\mathrm{H} 2$ but with larger molecular weight) was also assessed in immuno-PET studies. Biodistribution analyses revealed higher specific uptake levels in Hcc827-GR6 tumors than other groups. However, the image contrast was not improved due to higher background signal in the blood (Hcc827-GR6 tumor: blood $=4.2 \pm 0.5$ ) resulting from the longer persistence of the minibody in the serum. Overall, the H2 cys-diabody is the preferred choice for rapid immunoPET applications because it has the unique advantage of cross-reacting with mouse c-MET, thus allowing more representative imaging studies in the presence of endogenous c-MET expression in normal mouse tissues.

According to results of above studies, monoclonal antibodies or scFv specific to c-MET radiolabeled with the long half-life period positron-emitting radionuclide ${ }^{89} \mathrm{Zr}$ could precisely detect c-MET expression in vitro and in vivo in mice tumor model, and may prove to be an effective immuno-PET agent in humans.

In addition to antibody-based radiotracers, antibodybased fluorescent tracers have also been used for c-METtargeted molecular imaging in vivo to assess c-MET expression levels. In 2010, Lu et al. synthesized QD (quantum dot)-labeled anti-c-MET scFv (designated Ms20-QD) and tested its efficacy as an imaging agent in c-MET-expressing tumors [53]. The Ms20-QD synthesis was completed by site-directed conjugation of Ms20 cys to maleimideactivated quantum dots through its carboxy-terminal cysteine. In in vivo assays, xenografts in mice models derived from the human NSCLC cell line H1993, which has high expression levels of c-MET, were injected with Ms20-QD or non-conjugated QD and then imaged using a Xenogen IVIS 200 imaging system. At 6 h p.i., near-infrared (NIR) fluorescence signal intensity in the tumor tissues of Ms20QD-treated mice was approximately 3.6-fold higher than in QD-treated mice. Biodistribution at $24 \mathrm{~h}$ p.i. revealed that Ms20-QD selectively accumulated in the H1993 xenograft tumor tissues with 4.3-fold more than QD alone.

Towner and his group made important breakthroughs in the domain of c-MET-targeted MRI, which offers better reproducibility without any radiation damage. In 2008, the team successfully visualized overexpressed c-MET in C6 
(rat glioma) rat models in vivo by MRI based on a targeting contrast agent, anti-c-MET-Gd-DTPA-albumin, an anti-c-MET antibody linked to biotinylated Gd-DTPAalbumin [54]. T2-weighted images provided anatomical detail on tumor location, and T1-weighted images provided MR signal information of the Gd-based probe in glioma versus normal brain tissues. In contrast to MRI images collected before target agent administration, images taken at $3 \mathrm{~h}$ after injection of the anti-c-MET-GdDTPA-albumin showed that there was higher uptake in C6 tumor regions that persisted at least $24 \mathrm{~h}$ p.i. However, no significant temporal change in the MR signal was detected in the normal contralateral tissues. In addition, there were minimal changes in MR signal intensity and in $\mathrm{T} 1$ values in the $\mathrm{C} 6$ tumor region after administration of control probes, namely, non-Ab albumin-Gd-DTPA and a normal rat IgG-Gd-DTPA. Notably, a significant increase in MRI signal intensity in the outer regions of the glioma correlated with the vascular nature of the tumor, as described previously [55].

In another study [56], Towner et al. synthesized a molecular-targeted MRI contrast agent that could distinctively decrease MRI signal intensity and regional T2 values, by coupling SPIO (super paramagnetic iron oxide)-streptavidin to an anti-cMET antibody. SPIO-anti-c-MET was injected into a choline-deficient L-amino acid (CDAA)-defined rat hepatocarcinogenesis model and, for the first time, the expression of c-MET was visualized in vivo. A decrease in T2-weighted MRI signal, as well as changes in $\mathrm{T} 2$ values, were detected within selected regions of the tumor (expressing high c-MET), while two negative control groups including choline-sufficient L-amino acid (CSAA)-defined rats (normal c-MET levels) administered with the SPIO-anti-c-MET or with SPIO alone (without anti-c-MET antibody) showed no substantial changes in both T2 values or MRI signal intensities.

In 2010, Towner and colleagues reported another novel MRI molecular imaging probe for the in vivo detection of c-MET overexpression in C6 rat glioma models [57]. This probe, which consisted of a magnetitebased dextran-coated nanoparticle backbone covalently bound to an anti-c-MET antibody, also distinctively detected decreased MRI signal intensity and T2 values in tumor regions, when compared to normal tissue. As expected, the non-immune non-specific normal rat IgG coupled to dextran-coated nanoparticles control did not caused obvious changes in C6 tumor regions.

Based on data from above studies, Towner et al. initially developed these MRI contrast agents targeted to c-MET, and further illustrated that these anti-c-MET antibodybased targeting agents were feasible for detection of c-MET overexpression in tumor in vivo with MRI by changes in signal intensity. Despite this very valuable preclinical attempt to visualize c-MET using MRI, some limitations need to be considered such as nephrogenic systemic fibrosis (NSF) associated with MRI contrast agent Gd, immunogenicity from intact antibody [58]. On the other hand, nanoprobes based on SPIO possess higher security, with minimal impact on cell viability and function, and low toxicity [59].

\section{Molecular imaging agents based on peptides}

Compared to antibody-based c-MET-targeted molecular imaging, with inherent long clearance half-life after injection and potential immunogenicity, smaller peptidebased molecular imaging agents, due to their low molecular weight, present some advantages such as favorable pharmacokinetic and tissue distribution patterns, higher permeability, lower toxicity, less immunogenicity, and easy accessibility for chemical modification [60]. In recent years, a number of c-MET-targeted molecular probes based on a c-MET binding peptide (cMBP) have been developed that allow the visualization of c-MET expression in vivo.

In 2007, Zhao et al. searched for a cMBP from a random peptide phage display library using a subtractive planning approach on intact cells [61], and performed with a series of in vitro assays including competition ELISA, FACS analysis, cell internalization, and cell proliferation inhibition. They examined the specificity and binding affinity of the novel peptide, designated Metpep1. Met-pep1reacts with c-MET on the cell surface and competes with HGF binding to c-MET in a dosedependent manner. The authors tested Met-pep1 labeled with ${ }^{125} \mathrm{I}$ as a diagnostic tracer in vivo in xenografts in mice models of human leiomyosarcoma derived from the cell line SK-LMS-1/HGF, which expresses c-MET/ HGF. Tumor-associated radioactivity was detected by nuclear imaging as early as $1 \mathrm{~h}$ after injection of the tracer and remained visible up to $24 \mathrm{~h}$ p.i. Quantitative ROI analyses showed that tumor activity accounted for 4 to $5 \%$ of the estimated injected activity at 1 and $4 \mathrm{~h}$ p.i. but declined to $3 \%$ at $7 \mathrm{~h}$ p.i. However, tumor-associated radioactivity detected after injection of a control ${ }^{125} \mathrm{I}$-labeled non-avid peptide was significantly lower at all time points. These results demonstrated that Met-pep1 was specific to c-MET and might be a potential diagnostic agent for clinical applications. Activity was highest in the liver at all imaging time points, suggesting that the liver is major metabolic pathway for the tracer. Nevertheless, activity was also evident in the bladder at 4 and $7 \mathrm{~h}$ post-injection, whereas thyroid activity derived from deiodination of the tracer increased over time.

In 2009, Kim et al. reported a new cMBP identified on a peptide phage display system and then radiolabeled with ${ }^{125}$ I directly, with a radiochemical purity of $>90 \%$ [62]. As the biodistribution results showed that ${ }^{125} \mathrm{I}$ cMBP had low tumor-to-blood ratios (tumor/blood = 1.89 at 4 h p.i.), but a GGG (amino acid reducing hydrophilicity, tumor/blood $=2.94$ at $4 \mathrm{~h}$ p.i.) or an AOC 
(aliphatic carbon increasing lipophilicity, tumor/blood = 1.78 at $4 \mathrm{~h}$ p.i.) were introduced as a linker to the structure of radiotracer enhance the tumor-cell binding affinity. Blocking assays showed that the specific binding to U87-MG cells was significantly blocked by unlabeled cMBP, cMBP-GGG, and cMBP-AOC, respectively, but not by the mismatched peptide. According to the biodistribution data, ${ }^{125}$ I-cMBP-GGG exhibited the highest tumor-to-blood ratios and tumor uptake over time. Consistent with these data, SPECT images of U87-MG xenografts were clearer in mice injected with ${ }^{125} \mathrm{I}$-cMBPGGG. Unexpectedly, both cMBP-GGG and cMBP-AOC showed uniform high pancreatic uptake, which may be a result of peptide degradation, as there was very low cMET expression in the pancreas compared to tumor tissue, as confirmed by RT-PCR. In addition, introduction of the linker did not affect specificity of the probe to cMET, whereas a lower pancreatic uptake was observed. ${ }^{125} \mathrm{I}$-cMBP-GGG and ${ }^{125} \mathrm{I}$-cMBP-AOC could be cleared from body at $15 \mathrm{~h}$ p.i. mainly by renal metabolism. In the same year, based on the same peptide, Kim's group reported two other c-MET-targeted probes labeled with cyanine dye 5.5 (Cy5.5), Cy5.5-cMBP-GGG, and Cy5.5cMBP-AOC for optical imaging in athymic mice bearing U87-MG or Ramos (c-MET negative human Blymphoma) xenografts [63]. The Cy5.5-conjugated peptides bound mainly to the cell surface with high binding affinities and could be blocked by free cMBP. U87-MG tumors were clearly visualized with both these fluorescent probes, but cMBP-AOC-Cy5.5 displayed higher tumor uptake and tumor-to-normal tissue ratios from $10 \mathrm{~min}$ to $24 \mathrm{~h}$ p.i. (Fig. 3). When cMBP-AOC-Cy5.5 was co-injected with cold cMBP in in vivo blocking assays, the tumoral uptake decreased up to approximately $35 \%$. In a previous study, ${ }^{125}$ I-radiolabeled cMBP-GGG showed higher tumor uptake than cMBP-AOC [62]; however, tumor uptake was reversed by conjugation to Cy5.5. Indeed, while ${ }^{125} \mathrm{I}$-radiolabeled cMBPs showed high pancreatic uptake, Cy5.5 conjugates were instead rapidly eliminated via the renal metabolic pathway. These differences in retention might be related to the size or properties of Cy5.5, for instance, lower pancreatic uptake could be caused by Cy5.5 hydrolysis. In conclusion, Kim et al. tested this cMBP radiolabeled with ${ }^{125} \mathrm{I}$ or conjugated to Cy5.5 as a tracer with a different linker for visualization of c-MET. Results from these cMBPbased nuclear and optical images are in concordance, demonstrating that the cMBP-based tracer could accurately detect $\mathrm{c}-\mathrm{MET}$ overexpression.

More recently, Burggraaf et al. reported a novel optically labeled c-MET-targeted molecular imaging probe, designated GE-137, which has been assessed in a preclinical study as well as in healthy volunteers [64]. GE137 was prepared by conjugating a water-soluble 26amino acid cyclic peptide (AH-111972) with high affinity for c-MET $(K d=2 \mathrm{nM})$ to a linker $(\mathrm{GGGK})$ and subsequently to a modified Cy5 (Cy5\%*, $\lambda$ max ex $=648 \mathrm{~nm})$. Intravenous administration of GE-137 in mice bearing HT29 tumors (human colorectal cancer with positive cMET expression) resulted in specific accumulation of
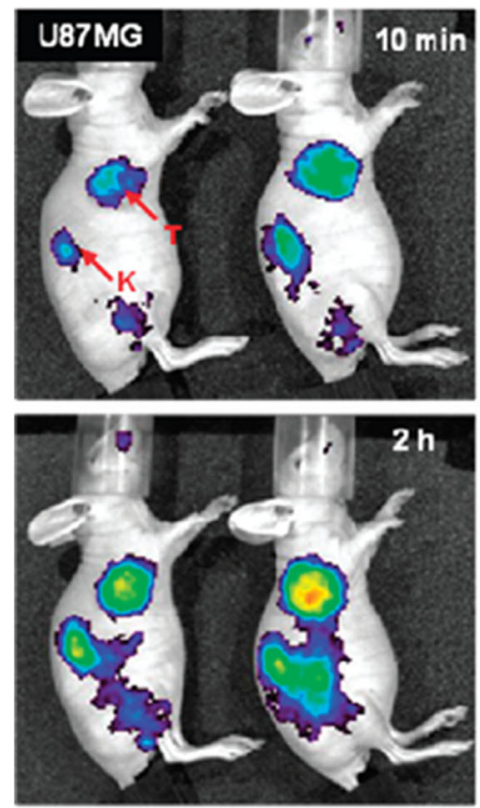
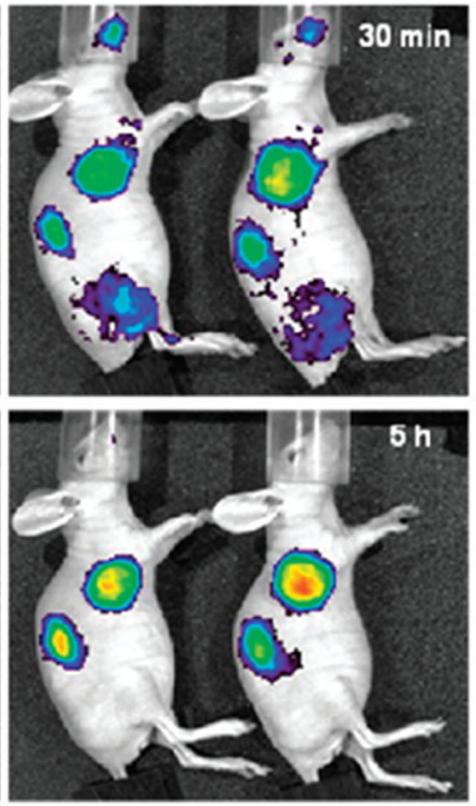
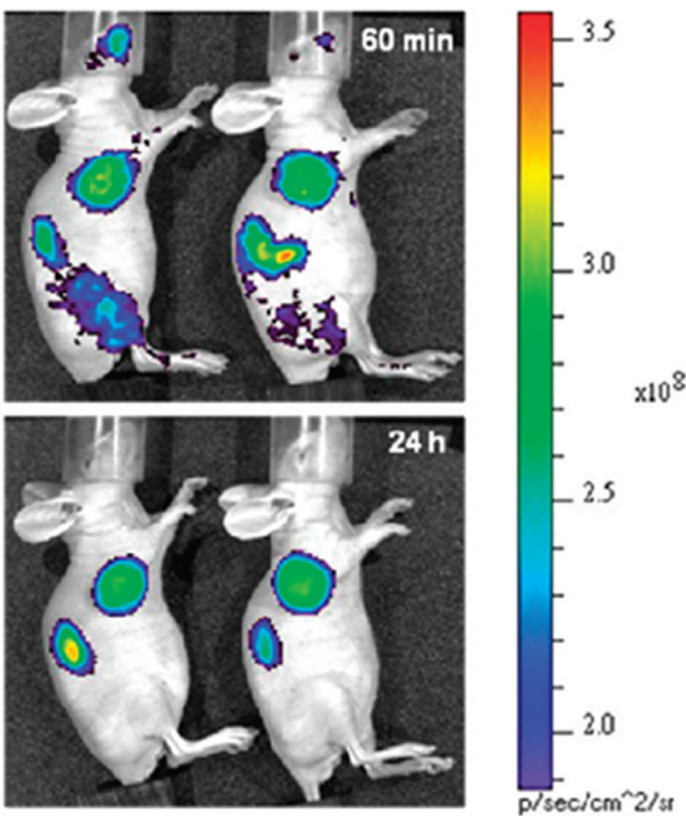

Fig. 3 In vivo fluorescence imaging of U87-MG bearing xenografts after iv injection of cMBP-GGG-Cy5.5 (left) or cMBP-AOC-Cy5.5 (right), of which red arrows indicate the tumor (T) or kidney (K). With permission from reference [63] 
the probe in c-MET expressing tumors, whereas $\mathrm{Cy} 5^{* *}$ labeled scrambled peptide as a control group was only visible in the kidneys. GE-137 has a dose-linear renal clearance, and the clearance rate was about $0.13 \mathrm{l} / \mathrm{kg} / \mathrm{h}$, and is comparable between dose groups. Plasma concentrations were $0.12-0.16 \mathrm{mg} / \mathrm{L}$ at $3 \mathrm{~h}$ after administration of $0.13 \mathrm{mg} / \mathrm{kg}$. In addition, co-administration of GE-137 with an excess of unlabeled peptides significantly reduced tumor uptake. After being validated as safe and well tolerated in healthy volunteers, GE-137 was tested in cancer patients. GE-137 visualized by fluorescence colonoscopy could detect not only all neoplastic polyps that were visible with white light but also additional polyps with c-MET expression, as verified by immunohistochemical analyses. This landmark first-in-human pilot study conducted by Burggraaf et al. showed that molecular imaging using an intravenous fluorescent cME- targeted agent is a feasible and safe method for clinical applications.

Liu et al. [65] showed using a fluorescent imaging device developed in-house that GE-137 specifically accumulated in SKOv3 (high c-MET expression human oophoroma) xenografts in mice and peaked at 2-3 h after injection, and lasted for up to $8 \mathrm{~h}$, whereas fluorescence intensity was comparatively lower in MUKA xenografts in mice (low c-MET expression human oophoroma). In addition, no accumulation of AH11444, a Cy5 derivative used as a negative control tracer, was observed in the tumor, further demonstrating the selectivity of GE-137 in tumor uptake. Strikingly, even submillimeter SKOv3 tumor deposits were observed subcutaneously in real time, revealing the high sensitivity of the fluorescence imaging device in detecting c-MET expressing tumors.

In summary, the novel fluorescent tracer based on cMET-targeted peptide (GE-137) has successfully visualized expression of c-MET in preclinical study and was further used to detect colorectal carcinoma overexpressing cMET in clinical setting. Furthermore, the peptide targeted against $\mathrm{c}$-MET was also labeled with radionuclides $\left({ }^{18} \mathrm{~F}\right.$, ${ }^{99 \mathrm{~m}} \mathrm{Tc}$ ) to detect expression of c-MET.

Based on these studies, in 2016, Arulappu et al. developed a radiolabeled analogue of GE-137, ${ }^{18}$ F-AH113804, synthesized with radiochemical purity of $>90 \%$ and specific activity of $100 \mathrm{GBq} / \mu \mathrm{mol}$ [66]. After validating the high affinity and specific binding of ${ }^{18} \mathrm{~F}$-AH113804 to c-MET (Kd $\approx$ 2nM) by ex vivo analyses and PET imaging, Arulappu and colleagues demonstrated that ${ }^{18} \mathrm{~F}$-AH113804-based PET imaging could detect loco-regional recurrences after surgical excision of orthotopically implanted HCC1954 human basal-like breast cancer with high c-MET expression in mice models as early as 6 days postoperatively, while with CT scanning, the recurrences could only be visualized after at least 20 days. These results showed that ${ }^{18} \mathrm{~F}$-AH113804based PET imaging has great potential as a clinical screening tool for earlier loco-regional recurrences of human basal-like breast cancer. Due to smaller molecular weight $(\sim 3.2 \mathrm{kDa}), 18$ F-AH113804 not only permitted early imaging after tracer administration ( $1 \mathrm{~h}$ p.i.) but also cleared fast from plasma and non-target tissues (such as liver, lungs, and heart), allowing for high-contrast imaging after injection, and improving the sensitivity for tumor detection.

Remarkably, Jagoda and colleagues not only conducted leading work in the development of antibody-based cMET-targeted molecular imaging but they also performed extensive research on molecular imaging based on cMBP $[67,68]$. The team was able to modify a 26 -amino acid cMBP AH-111972 at the C-terminal lysine with cPn216 chelating for ${ }^{99 \mathrm{~m}} \mathrm{Tc}$, or with tetra $\mathrm{SO}_{3}$ for labeling with cy5*: $(653 / 675 \mathrm{~nm}) .{ }^{99 \mathrm{~m}} \mathrm{Tc}-\mathrm{cMBP}$ was synthesized with radiochemical purity of $>90 \%$ and specific activity of $430 \mathrm{Ci} / \mathrm{mmol}$, and with high affinity binding (nM) to cMET observed in vitro in MKN-45 (high c-MET expression). In biodistribution assays of MKN-45 xenografts in mice models, higher uptake of ${ }^{99 \mathrm{~m}} \mathrm{Tc}$-cMBP was detected in MKN-45 xenografts than all organs except for the kidney. Blocking studies showed that tumor uptake decreased by $62 \%$ after coinjection of ${ }^{99 \mathrm{~m}} \mathrm{Tc}$-cMBP with $24 \mathrm{nmol}$ of unlabelled cMBP. In initial microSPECT imaging studies, the tumor could be visualized as early as $30 \mathrm{~min}$ p.i. and clearly at $60 \mathrm{~min}$ p.i., and the images remained relatively constant until $120 \mathrm{~min}$ p.i. but then the signal significantly decreased. Measurements of tumor vs background signal indicated that the optimal imaging time for ${ }^{99 \mathrm{~m}} \mathrm{Tc}$-cMBP was $90 \mathrm{~min}$ p.i., and this time point was therefore adopted in subsequent longitudinal imaging studies for assessing the ability of ${ }^{99 \mathrm{~m}} \mathrm{Tc}$-cMBP to monitor targeted therapy in MKN-45 xenografts with c-MET TKI PHA665752. ${ }^{99 \mathrm{~m}} \mathrm{Tc}-$ cMBP tumor uptake in the treated group, when compared to the vehicle group, was decreased by 43,42 , and $25 \%$ at days 8,14 , and 21 , respectively. Notably, these results were comparable to cy5\%-cMBP fluorescence imaging using the same treatment models with an optimal dose of $1 \mathrm{nmol}$ and optimal imaging time of $60 \mathrm{~min}$ p.i.., and this was validated by histologic and immunohistochemical analyses. ${ }^{99 \mathrm{~m}} \mathrm{Tc}$-cMBP and cy $5 *$-cMBP imaging may therefore have clinical applications in diagnostic and therapeutic monitoring in the future.

\section{Molecular imaging agents based on genetically encoded proteins}

The strategies that whole body optical (e.g. fluorescence, bioluminescence) imaging based on genetically encoded proteins have been critically evaluated as a feasible molecular imaging modality in cells and transgenic animals, enabling noninvasive, longitudinal studies of dynamic biological processes in vivo $[69,70]$. 
In 2011, a study by Zhang et al. reported a novel method for c-MET-targeted molecular imaging and therapy monitoring based on gene transfected mice models [71]. Plasmids carrying bioluminescent reporters for wild type cMET (BMRwt) or c-METY530A (BMRmut) that turned OFF when c-MET was active/phosphorylated, and ON when c-MET was inhibited, were constructed and then stably transfected into human glioma cell lines D54 and U87MG (both with c-MET expression) to assess their ability for detecting changes in c-MET expression. U87-BMRwt cells that were treated with increasing doses of the c-MET inhibitor SU11274 exhibited increased bioluminescence activity in a dose-dependent manner, peaking at $15 \mathrm{~min}$ before plateauing thereafter. In contrast, cells transfected with BMRmut, which are resistant to SU11274, had no significant change in bioluminescence activity in response to SU11274 treatment. In vivo assays in murine models using an IVIS imaging system showed that tumors in control antibody-treated animals had no significant increase in bioluminescence activity after SU11274 administration, while HGF neutralizing antibody-treated tumors had a 4- to 5fold increase in bioluminescence activity at $3 \mathrm{~h}$ p.i. and sustained for $10 \mathrm{~h}$.

In 2006, another method for c-MET-targeted molecular imaging based on genetic engineering was developed [72]. In this study, Moshitch-Moshkovitz et al. constructed a GFP (green fluorescent protein)-Met chimeric molecule that functioned similarly to wild type c-MET, and then generated GFP-c-MET transgenic mice. These mice ubiquitously expressed GFP-Met in specific epithelial and endothelial cells and displayed enhanced GFP-Met fluorescence in sebaceous glands with the fact that $32 \%$ of the males spontaneously developed adenomas, adenocarcinomas, and angiosarcomas in their lower abdominal sebaceous glands. Quantitative subcellular resolution intravital imaging revealed very high levels of GFP-c-MET in tumor lesions and in single isolated cells surrounding them, relative to normal sebaceous glands. These single cells with higher GFP-c-MET levels were correlated to early tumor aggressiveness and preceded the formation of local and distal metastases.

\section{Molecular imaging agents based on anticalins}

Anticalins are a novel class of protein-based biopharmaceuticals that due to their small size $(17 \mathrm{kDa})$ may have more favorable tumor uptake and penetration when compared with the much larger IgGs $(150 \mathrm{kDa})$, and therefore display highly desirable attributes as molecular imaging agents. Terwisscha van Scheltinga et al. engineered PRS-110, an anticalin with monovalent specificity for c-MET (binding affinity of $0.6 \mathrm{nmol} / \mathrm{L}$ ), which is site-specifically conjugated to a branched $40-\mathrm{kDa}$ polyethyleneglycol (PEG) $(2 \cdot 20 \mathrm{kDa}$ PEG) moiety for half-life prolongation [73, 74]. A phase I trial in cancer patients supports the use of the anticalin drug platform for broad therapeutic and diagnostic applications [75]. To visualize in vivo c-MET expression and study the organ distribution of this anticalin, Terwisscha van Scheltinga and colleagues generated ${ }^{89} \mathrm{Zr}$-PRS-110 with a specific activity of $100 \mathrm{MBq} / \mathrm{mg}$ and radiochemical purity of $>95 \%$ and assessed its specific uptake in different human tumor xenograft models. Ex vivo assays showed that increasing doses of unlabeled PRS-110 led to tumor saturation and to specific blockade of ${ }^{89} \mathrm{Zr}$-PRS-110 uptake. PET imaging performed in $\mathrm{H} 441$ bearing mice (human NSCLC with high c-MET expression) with a suitable concentration of the tracer revealed that tumor uptake peaked at $48 \mathrm{~h}$ p.i. (Fig. 4) and showed a significantly higher uptake of ${ }^{89} \mathrm{Zr}$ PRS-110 when compared to ${ }^{89} \mathrm{Zr}$-Tlc-PEG (non-c-MET binding), in line with the ex vivo biodistribution data (5.9 vs. $3.9 \% \mathrm{ID} / \mathrm{g}$ ). In A2780 bearing mice (human ovarian cancer with negative c-MET expression), both ${ }^{89} \mathrm{Zr}$-PRS-110 and ${ }^{89} \mathrm{Zr}$-Tlc-PEG were aggregated up to a similar extent (1.7 and $2.5 \% \mathrm{ID} / \mathrm{g}$ respectively), with lower uptake than H441 tumors. Overall, there was a significant correlation between ex vivo biodistribution and small-animal PET data quantification $\left(R^{2}=0.812 ; P<0.05\right)$. In addition, uptake of ${ }^{89} \mathrm{Zr}$-PRS-110 and ${ }^{89} \mathrm{Zr}$-Tlc-PEG in various organs was comparable, except for the lung. Lung uptake of ${ }^{89} \mathrm{Zr}$-PRS110 in mice bearing H441 tumors occurred neither in A2780 tumors with ${ }^{89} \mathrm{Zr}$-PRS-110 nor in any of the two xenografts with the negative control ${ }^{89} \mathrm{Zr}$-Tlc-PEG. The decreased uptake in the absence of c-MET and for the nonbinding control demonstrates a c-MET-associated mechanism of uptake in the lung (possibly metastasis), which needs further investigation.

Anticalin is a novel biopharmaceutical with good drug properties that may be applied extensively in the clinic, as anticalin-based molecular imaging could not only be useful for the diagnosis at the molecule level but also enable real-time monitoring of anticalin metabolic pathways (e.g., PRS-110) and pharmacokinetics, thus having a dual role in molecular imaging and drug development.

\section{Molecular imaging agents based on small molecules}

The binding sites for the imaging tracers described above are all located on the extracellular domain of the c-MET receptor; however, the initial molecular event that leads to malignant development is the abnormal activation of the receptor's tyrosine kinases, which are located in the intracellular domain of c-MET, and which will ultimately trigger downstream signaling pathways. Thus, molecular imaging based on small molecule probes with intracellular binding site can provide more roundly information about the c-MET activation status. Small molecule imaging probes, with their low molecular weight and size, are rapidly cleared and have higher permeability, and in particular, those based on c-METTKI have attractive properties, such as being non-toxic 


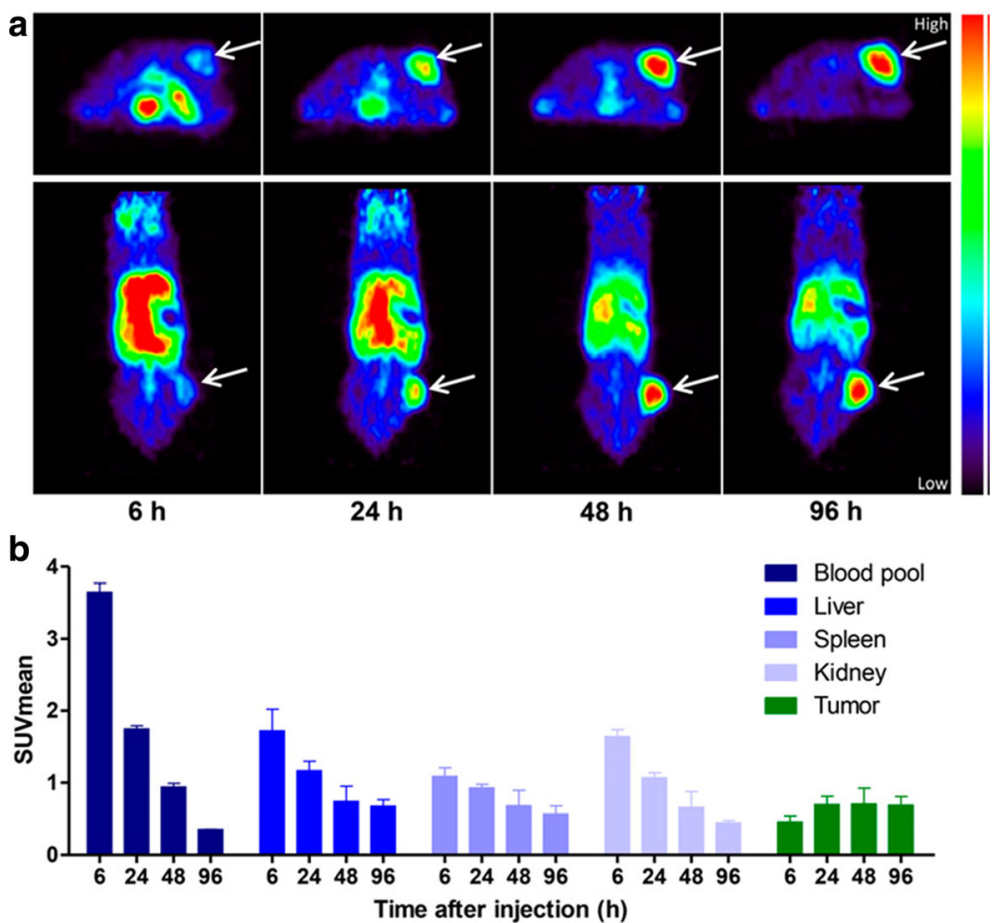

Fig. $4^{89} \mathrm{Zr}$-PRS-110 micro-PET imaging of H441-bearing mice. a Transversal and coronal micro-PET images of the mice are shown at different timepoint post-injection of tracer. b Micro-PET data quantification expressed as mean standardized uptake value (SUVmean) was performed for normal organ and tumor in all mice. With permission from reference [74]

and easily accessible for clinical translation. However, to date, little progresses have been made in the development of small molecule imaging agents.

The first reported study by Wu et al. in 2010 [76] described the small molecule c-MET-TKI SU11274, a reversible c-MET inhibitor that was designed and synthesized as a labeling precursor and was subsequently methylated with ${ }^{11} \mathrm{C}$-methyl iodide to produce ${ }^{11} \mathrm{C}$-SU11274 with radiochemical purity of $\geq 98 \%$ and a specific activity of $0.3-0.5 \mathrm{Ci} / \mathrm{mmol} .{ }^{11} \mathrm{C}-\mathrm{SU} 11274$ has the same structure as SU11274, and therefore, its binding affinity and specificity was preserved. Then the authors tested ${ }^{11} \mathrm{C}$-SU11274 as a micro-PET imaging agent for c-MET expression in vivo. They showed that tumor uptake of ${ }^{11} \mathrm{C}-\mathrm{SU} 11274$ in cMET-positive H1975 bearing mice (human NSCLC) was significantly higher than that in c-MET-negative H520 (human NSCLC) xenografts. Specifically, tumor uptake of ${ }^{11} \mathrm{C}-\mathrm{SU} 11274$ in $\mathrm{H} 1975$ peaked up at $80 \mathrm{~min}$ p.i. and was always higher than that in H520. These results not only confirmed the feasibility of using ${ }^{11} \mathrm{C}-\mathrm{SU} 11274$ as a PET tracer for c-MET activation but also revealed the importance of the tracer to study pharmacokinetics of SU11274.

The slow progress in the development of small molecule imaging agents based on c-MET-TKI could mainly be attributed to challenges in the modification and synthesis of the probes. Indeed, the synthesis of the labeling precursor, which is modified from the small molecule c-MET-TKI, should produce a structure that is same or similar to the parent drug after labeling, in order to preserve the specificity to the target. Moreover, the labeling reaction requires a very complex and precise technique that is crucial to synthesize stable and pure imaging tracers.

\section{Conclusions}

In this review, we have provided a brief historical overview of the development of c-MET-targeted imaging agents, from mAbs to small molecules. Evidently, each substrate, whether it is an endogenous ligand, antibody, peptide, or small molecule, has unique advantages and limitations. While radiolabeled mAbs such as ${ }^{89} \mathrm{Zr}$ - df-onartuzumab have shown promise in preclinical studies, smaller structures like anticalin and peptides also demonstrated similarly desirable in vivo properties, making them compatible for radiolabeling with the more popular radionuclides ${ }^{18} \mathrm{~F}$ or ${ }^{99 \mathrm{~m}} \mathrm{Tc}$, which have shorter half-lives and have been extensively used in clinical applications.

In general, various types of molecular probe have distinctive advantages and disadvantages. For example, antibody-based probes have high binding affinity but with long metabolic cycle and immunogenicity. And small molecule probes have advantages in size, pharmacokinetics, and security, but are inadequate for delayed imaging after injection, due to fast clearance. Regarding the imaging technique, nuclear imaging (e.g., PET, 
SPECT) are useful for imaging whole body and deep viscera, whereas optical imaging (e.g., fluorescence, bioluminescence) is mainly applied in detecting superficial organs and endoscopic procedures, due to weak penetrability of fluorescence signal.

In our opinion, after clinical application of GE-137 with encouraging results for detection of malignant polyps, the field of c-MET-targeted molecular imaging will hopefully become established in the clinic with many expected research results in preclinical studies. Other strategies which might be relevant for translation into the clinic are antibody (fragment) tracers, as companion diagnostics for their parental antibody therapies [77]. Although studies for c-MET-targeted molecular imaging have made many important advances, most of imaging agents specifically target to extracellular area of c-MET, so it can only reflect overexpression of c-MET. Nevertheless, imaging agents based on small molecule cMET-TKI possess intracellular binding site as well as many advantages, thus should be paid more attention.

c-MET-targeted molecular imaging makes it possible to visualize the abnormal alteration of c-MET expression in vivo and in real time, with the potential applications such as patient screening for c-MET-targeted therapeutics, monitoring therapeutic effects, evaluating prognosis, and analysis for resistance mechanism. Although the optimization of c-MET-targeted molecular imaging for clinical purposes still faces many challenges, the recent advances in the field, together with its potential clinical benefits, are highly encouraging for future research.

\begin{abstract}
Abbreviations
\%EIA: Percentage of estimated injected activity; BOLD: Blood oxygenation level dependent; CDAA: Choline-deficient L-amino acid; CMBP: C-MET binding peptide; CMET: Mesenchymal-epithelial transition factor; CSAA: Choline-sufficient, L-amino acid; EGFR: Epidermal growth factor receptor; ELISA: Enzyme-linked immuno sorbent assay; Fab: Antigen-binding fragment; FACS: Fluorescence-activated cell sorter; FISH: Fluorescent in situ hybridization; GFP: Green fluorescent protein; HER2: Human epidermalgrowth factor receptor-2; HER3: Human epidermalgrowth factor receptor-3; HGF: Hepatocyte growth factor; IgG: Immunoglobulin G; mAbs: Monoclonal antibodies; MAPK: Mitogen-activated protein kinase; MRl: Magnetic resonance imaging; NSCLC: Non-small-cell lung cancer; NSF: Nephrogenic systemic fibrosis; PcAb: Polyclonal antibody; PDGFR: Plateletderived growth factor receptor; PEG: Polyethyleneglycol; PET: Positron emission tomography; QD: Quantum dot; RAS: Rat sarcoma; ROI: Region of interest; RON: Recepteur d'origine nantais; RTK: Receptor tyrosine kinase; RT-PCR: Reverse transcription-polymerase chain reaction; SPECT: Single photon emission computed tomography; SPIO: Super paramagnetic iron oxide; TKI: Tyrosine kinase inhibitor
\end{abstract}

\footnotetext{
Acknowledgements

This work was supported by the National Basic Research Program of China (2015CB931800), the National Natural Science Foundation of China (81471724, 81101088, 81130028, 31210103913), Innovation Fund Designated of Harbin (2014RFQGJ011), Heilongjiang Province Department of Education Science and Technology Research Projects (12521184), the Youth Science WU LIANDE Foundation of Harbin Medical University (WLD-QN1119), the Fourth Hospital of Harbin Medical University Fund for Distinguished Young Scholars, and the Key Laboratory of Molecular Imaging Foundation (College of Heilongjiang Province).
}

\section{Authors' contributions}

BS initiated and oversaw the project. All authors were responsible for the article. The manuscript was drafted by ZH, XS, and YW and was discussed and critically revised by BS, ZC, and XS. YW and YX provided help for collecting the material. KW gave administrative support. All authors approved the final draft of the manuscript.

\section{Competing interests}

The authors declare that they have no competing interests.

\section{Consent for publication}

Not applicable.

\section{Ethics approval and consent to participate}

No studies with human participants or animals performed by any of the authors were included in the article.

\section{Publisher's Note}

Springer Nature remains neutral with regard to jurisdictional claims in published maps and institutional affiliations.

\section{Author details}

${ }^{1}$ Molecular Imaging Research Center, Harbin Medical University, 766Xiangan N street, Songbei District, Harbin, Heilongjiang 150028, China. ${ }^{2}$ TOF-PET/CT/ MR center, The Fourth Hospital of Harbin Medical University, Harbin, Heilongjiang, China. ${ }^{3}$ Molecular Imaging Program at Stanford (MIPS), Department of Radiology, Stanford University School of Medicine, Lucas Center, Room P089, 1201 Welch Rd, Stanford, CA 94305-5484, USA.

Received: 24 December 2016 Accepted: 17 April 2017

Published online: 08 May 2017

\section{References}

1. Cooper CS, Park M, Blair DG, Tainsky MA, Huebner K, Croce CM, et al. Molecular cloning of a new transforming gene from a chemically transformed human cell line. Nature. 1984;311:29-33.

2. Comoglio PM, Giordano S, Trusolino L. Drug development of MET inhibitors: targeting oncogene addiction and expedience. Nat Rev Drug Discov. 2008; 7:504-16.

3. Gherardi E, Youles ME, Miguel RN, Blundell TL, lamele L, Gough J, et al. Functional map and domain structure of MET, the product of the c-met protooncogene and receptor for hepatocyte growth factor/scatter factor. Proc Natl Acad Sci U S A. 2003;100:12039-44.

4. Nakamura T, Nishizawa T, Hagiya M, Seki T, Shimonishi M, Sugimura A, et al. Molecular cloning and expression of human hepatocyte growth factor. Nature. 1989:342:440-3.

5. Miyazawa K, Tsubouchi H, Naka D, Takahashi K, Okigaki M, Arakaki N, et al. Molecular cloning and sequence analysis of cDNA for human hepatocyte growth factor. Biochem Biophys Res Commun. 1989;163:967-73.

6. Stoker M, Gherardi E, Perryman M, Gray J. Scatter factor is a fibroblastderived modulator of epithelial cell mobility. Nature. 1987;327:239-42.

7. Bottaro DP, Rubin JS, Faletto DL, Chan AM, Kmiecik TE, Vande Woude GF, et al. Identification of the hepatocyte growth factor receptor as the c-met proto-oncogene product. Science. 1991;251:802-4.

8. Birchmeier C, Birchmeier W, Gherardi E, Vande Woude GF. Met, metastasis, motility and more. Nat Rev Mol Cell Biol. 2003;4:915-25.

9. Rodrigues GA, Park M. Autophosphorylation modulates the kinase activity and oncogenic potential of the Met receptor tyrosine kinase. Oncogene. 1994;9:2019-27.

10. Fixman ED, Fournier TM, Kamikura DM, Naujokas MA, Park M. Pathways downstream of Shc and Grb2 are required for cell transformation by the tpr-Met oncoprotein. J Biol Chem. 1996;271:13116-22.

11. Pelicci G, Giordano S, Zhen Z, Salcini AE, Lanfrancone L, Bardelli A, et al. The motogenic and mitogenic responses to HGF are amplified by the Shc adaptor protein. Oncogene. 1995;10:1631-8

12. Sakkab D, Lewitzky M, Posern G, Schaeper U, Sachs M, Birchmeier W, et al. Signaling of hepatocyte growth factor/scatter factor (HGF) to the small GTPase Rap1 via the large docking protein Gab1 and the adapter protein CRKL. J Biol Chem. 2000;275:10772-8. 
13. Garcia-Guzman M, Dolfi F, Zeh K, Vuori K. Met-induced JNK activation is mediated by the adapter protein Crk and correlates with the Gab1-Crk signaling complex formation. Oncogene. 1999;18:7775-86.

14. Organ SL, Tsao MS. An overview of the c-MET signaling pathway. Ther Adv Med Oncol. 2011;3:S7-19.

15. Trusolino L, Bertotti A, Comoglio PM. MET signalling: principles and functions in development, organ regeneration and cancer. Nat Rev Mol Cell Biol. 2010;11:834-48.

16. Liu X, Yao W, Newton RC, Scherle PA. Targeting the c-MET signaling pathway for cancer therapy. Expert Opin Investig Drugs. 2008;17:997-1011.

17. Peruzzi B, Bottaro DP. Targeting the c-Met signaling pathway in cancer. Clin Cancer Res. 2006;12:3657-60.

18. Paumelle R, Tulasne D, Kherrouche Z, Plaza S, Leroy C, Reveneau S, et al. Hepatocyte growth factor/scatter factor activates the ETS1 transcription factor by a RAS-RAF-MEK-ERK signaling pathway. Oncogene. 2002;21:2309-19.

19. Xiao GH, Jeffers M, Bellacosa A, Mitsuuchi Y, Vande Woude GF, Testa JR. Anti-apoptotic signaling by hepatocyte growth factor/Met via the phosphatidylinositol 3-kinase/Akt and mitogen-activated protein kinase pathways. Proc Natl Acad Sci U S A. 2001;98:247-52.

20. Krause DS, Van Etten RA. Tyrosine kinases as targets for cancer therapy. N Engl J Med. 2005;353:172-87.

21. Christensen JG, Burrows J, Salgia R. c-Met as a target for human cancer and characterization of inhibitors for therapeutic intervention. Cancer Lett. 2005;225:1-26.

22. Weidner KM, Behrens J, Vandekerckhove J, Birchmeier W. Scatter factor: molecular characteristics and effect on the invasiveness of epithelial cells. J Cell Biol. 1990;111:2097-108.

23. Rosen EM, Goldberg ID. Regulation of angiogenesis by scatter factor. EXS. 1997:79:193-208.

24. Abounader R, Lal B, Luddy C, Koe G, Davidson B, Rosen EM, et al. In vivo targeting of SF/HGF and c-met expression via U1snRNA/ribozymes inhibits glioma growth and angiogenesis and promotes apoptosis. FASEB J. 2002;16:108-10.

25. Danilkovitch-Miagkova A, Zbar B. Dysregulation of Met receptor tyrosine kinase activity in invasive tumors. J Clin Invest. 2002;109:863-7.

26. Wang R, Ferrell LD, Faouzi S, Maher JJ, Bishop JM. Activation of the Met receptor by cell attachment induces and sustains hepatocellular carcinomas in transgenic mice. J Cell Biol. 2001;153:1023-34.

27. Jo M, Stolz DB, Esplen JE, Dorko K, Michalopoulos GK, Strom SC. Cross-talk between epidermal growth factor receptor and c-Met signal pathways in transformed cells. J Biol Chem. 2000;275:8806-11.

28. Puri N, Salgia R. Synergism of EGFR and c-Met pathways, cross-talk and inhibition, in non-small cell lung cancer. J Carcinog. 2008;7:9.

29. Bachleitner-Hofmann T, Sun MY, Chen $C T$, Tang $L$, Song L, Zeng Z, et al. HER kinase activation confers resistance to MET tyrosine kinase inhibition in MET oncogene-addicted gastric cancer cells. Mol Cancer Ther. 2008;7:3499-508.

30. Follenzi A, Bakovic S, Gual P, Stella MC, Longati P, Comoglio PM. Cross-talk between the proto-oncogenes Met and Ron. Oncogene. 2000;19:3041-9.

31. Yeh CY, Shin SM, Yeh HH, Wu TJ, Shin JW, Chang TY, et al. Transcriptional activation of the Axl and PDGFR-alpha by c-Met through a ras- and Srcindependent mechanism in human bladder cancer. BMC Cancer. 2011;11:139.

32. Furge KA, Kiewlich $D$, Le $P$, Vo $M N$, Faure $M$, Howlett $A R$, et al. Suppression of Ras-mediated tumorigenicity and metastasis through inhibition of the Met receptor tyrosine kinase. Proc Natl Acad Sci U S A. 2001;98:10722-7.

33. Liu X, Newton RC, Scherle PA. Developing c-MET pathway inhibitors for cancer therapy: progress and challenges. Trends Mol Med. 2010;16:37-45.

34. Mueller KL, Hunter LA, Ethier SP, Boerner JL. Met and c-Src cooperate to compensate for loss of epidermal growth factor receptor kinase activity in breast cancer cells. Cancer Res. 2008:68:3314-22.

35. Sano $Y$, Hashimoto E, Nakatani N, Abe M, Satoh Y, Sakata K, et al. Combining onartuzumab with erlotinib inhibits growth of non-small cell lung cancer with activating EGFR mutations and HGF overexpression. Mol Cancer Ther. 2015;14:533-41.

36. Spigel DR, Edelman MJ, O'Byrne K, Paz-Ares L, Mocci S, Phan S, et al. Results from the phase III randomized trial of onartuzumab plus erlotinib versus erlotinib in previously treated stage IIIB or IV non-small-cell lung cancer: METLung. J Clin Oncol. 2017;35:412-20.

37. Yang $\mathrm{R}$, Bunting $\mathrm{S}, \mathrm{Ko} \mathrm{A}$, Schwall $\mathrm{R}$, Jin $\mathrm{H}$. Hemodynamic effects of scatter factor in conscious rats. J Cardiovasc Pharmacol. 1997;30:294-301.
38. Kaplan O, Firon M, Vivi A, Navon G, Tsarfaty I. HGF/SF activates glycolysis and oxidative phosphorylation in DA3 murine mammary cancer cells. Neoplasia. 2000;2:365-77.

39. Shaharabany M, Abramovitch R, Kushnir T, Tsarfaty G, Ravid-Megido M, Horev J, et al. In vivo molecular imaging of met tyrosine kinase growth factor receptor activity in normal organs and breast tumors. Cancer Res. 2001;61:4873-8.

40. Tsarfaty G, Stein GY, Moshitch-Moshkovitz S, Kaufman DW, Cao B, Resau JH, et al. HGF/SF increases tumor blood volume: a novel tool for the in vivo functional molecular imaging of Met. Neoplasia. 2006:8:344-52.

41. Luo $H$, Hong $H$, Slater MR, Graves SA, Shi S, Yang Y, et al. PET of c-Met in cancer with 64Cu-labeled hepatocyte growth factor. J Nucl Med. 2015;56:758-63.

42. Corcoran EB, Hanson RN. Imaging EGFR and HER2 by PET and SPECT: a review. Med Res Rev. 2014;34:596-643.

43. Hay RV, Cao B, Skinner RS, Wang LM, Su Y, Resau JH, et al. Radioimmunoscintigraphy of tumors autocrine for human met and hepatocyte growth factor/scatter factor. Mol Imaging. 2002;1:56-62.

44. Hay RV, Cao B, Skinner RS, Su Y, Zhao P, Gustafson MF, et al. Nuclear imaging of Met-expressing human and canine cancer xenografts with radiolabeled monoclonal antibodies (MetSeek). Clin Cancer Res. 2005;11:7064s-9.

45. Hay RV, Cao B, Skinner RS, Wang LM, Su Y, Resau JH, et al. Radioimmunoscintigraphy of human met-expressing tumor xenografts using met 3 , a new monoclonal antibody. Clin Cancer Res. 2003:9:38395-44.

46. Jiao Y, Zhao P, Zhu J, Grabinski T, Feng Z, Guan X, et al. Construction of human naive Fab library and characterization of anti-met Fab fragment generated from the library. Mol Biotechnol. 2005;31:41-54.

47. Knudsen BS, Zhao P, Resau J, Cottingham S, Gherardi E, Xu E, et al. A novel multipurpose monoclonal antibody for evaluating human c-Met expression in preclinical and clinical settings. Appl Immunohistochem Mol Morphol. 2009;17:57-67.

48. Divgi CR, Pandit-Taskar N, Jungbluth AA, Reuter VE, Gonen M, Ruan S, et al. Preoperative characterisation of clear-cell renal carcinoma using iodine-124labelled antibody chimeric G250 (124l-cG250) and PET in patients with renal masses: a phase I trial. Lancet Oncol. 2007;8:304-10.

49. Rahmim A, Zaidi H. PET versus SPECT: strengths, limitations and challenges. Nucl Med Commun. 2008;29:193-207.

50. Perk LR, Stigter-van Walsum M, Visser GW, Kloet RW, Vosjan MJ, Leemans CR, et al. Quantitative PET imaging of Met-expressing human cancer xenografts with 89Zr-labelled monoclonal antibody DN30. Eur J Nucl Med Mol Imaging. 2008;35:1857-67.

51. Jagoda EM, Lang L, Bhadrasetty $V$, Histed S, Williams M, Kramer-Marek G, et al. Immuno-PET of the hepatocyte growth factor receptor Met using the 1armed antibody onartuzumab. J Nucl Med. 2012;53:1592-600.

52. Li K, Tavare R, Zettlitz KA, Mumenthaler SM, Mallick P, Zhou Y, et al. AntiMET immunoPET for non-small cell lung cancer using novel fully human antibody fragments. Mol Cancer Ther. 2014;13:2607-17.

53. Lu RM, Chang YL, Chen MS, Wu HC. Single chain anti-c-Met antibody conjugated nanoparticles for in vivo tumor-targeted imaging and drug delivery. Biomaterials. 2011;32:3265-74.

54. Towner RA, Smith N, Doblas S, Tesiram Y, Garteiser P, Saunders D, et al. In vivo detection of c-Met expression in a rat C6 glioma model. J Cell Mol Med. 2008;12:174-86.

55. Doblas S, Saunders D, Kshirsagar P, Pye Q, Oblander J, Gordon B, et al. Phenyltert-butylnitrone induces tumor regression and decreases angiogenesis in a C6 rat glioma model. Free Radic Biol Med. 2008;44:63-72.

56. Towner RA, Smith N, Tesiram YA, Abbott A, Saunders D, Blindauer R, et al. In vivo detection of c-MET expression in a rat hepatocarcinogenesis model using molecularly targeted magnetic resonance imaging. Mol Imaging. 2007;6:18-29.

57. Towner RA, Smith N, Asano Y, Doblas S, Saunders D, Silasi-Mansat R, et al. Molecular magnetic resonance imaging approaches used to aid in the understanding of the tissue regeneration marker Met in vivo: implications for tissue engineering. Tissue Eng Part A. 2010;16:365-71.

58. Hasebroock KM, Serkova NJ. Toxicity of MRI and CT contrast agents. Expert Opin Drug Metab Toxicol. 2009;5:403-16.

59. Thorek DL, Chen AK, Czupryna J, Tsourkas A. Superparamagnetic iron oxide nanoparticle probes for molecular imaging. Ann Biomed Eng. 2006;34:23-38.

60. Chen $\mathrm{K}$, Chen $\mathrm{X}$. Design and development of molecular imaging probes. Curr Top Med Chem. 2010;10:1227-36. 
61. Zhao P, Grabinski T, Gao C, Skinner RS, Giambernardi T, Su Y, et al. Identification of a met-binding peptide from a phage display library. Clin Cancer Res. 2007;13:6049-55.

62. Kim EM, Park EH, Cheong SJ, Lee CM, Kim DW, Jeong HJ, et al. Characterization, biodistribution and small-animal SPECT of I-125-labeled cMet binding peptide in mice bearing c-Met receptor tyrosine kinasepositive tumor xenografts. Nucl Med Biol. 2009;36:371-8.

63. Kim EM, Park EH, Cheong SJ, Lee CM, Jeong HJ, Kim DW, et al. In vivo imaging of mesenchymal-epithelial transition factor (c-Met) expression using an optical imaging system. Bioconjug Chem. 2009; 20:1299-306.

64. Burggraaf J, Kamerling IM, Gordon PB, Schrier L, de Kam ML, Kales AJ, et al. Detection of colorectal polyps in humans using an intravenously administered fluorescent peptide targeted against c-Met. Nat Med. 2015;21:955-61.

65. Liu S, Zheng Y, Volpi D, El-Kasti M, Klotz D, Tullis I, et al. Toward operative in vivo fluorescence imaging of the c-Met proto-oncogene for personalization of therapy in ovarian cancer. Cancer. 2015;121:202-13.

66. Arulappu A, Battle M, Eisenblaetter M, McRobbie G, Khan I, Monypenny J, et al. c-Met PET imaging detects early-stage locoregional recurrence of basallike breast cancer. J Nucl Med. 2016;57:765-70.

67. Garcia-Allende PB, Glatz J, Koch M, Ntziachristos V. Enriching the interventional vision of cancer with fluorescence and optoacoustic imaging. J Nucl Med. 2013;54:664-7.

68. Jagoda EM, Bhattacharyya S, Kalen J, Riffle L, Leeder A, Histed S, et al. Imaging the Met receptor tyrosine kinase (Met) and assessing tumor responses to a Met tyrosine kinase inhibitor in human xenograft mouse models with a [99mTc] (AH-113018) or Cy 5** (AH-112543) labeled peptide. Mol Imaging. 2015;14:499-515.

69. Gross S, Piwnica-Worms D. Spying on cancer: molecular imaging in vivo with genetically encoded reporters. Cancer Cell. 2005;7:5-15.

70. Razgulin A, Ma N, Rao J. Strategies for in vivo imaging of enzyme activity: an overview and recent advances. Chem Soc Rev. 2011;40:4186-216.

71. Zhang L, Virani S, Zhang Y, Bhojani MS, Burgess TL, Coxon A, et al. Molecular imaging of c-Met tyrosine kinase activity. Anal Biochem. 2011;412:1-8.

72. Moshitch-Moshkovitz S, Tsarfaty G, Kaufman DW, Stein GY, Shichrur K, Solomon $E$, et al. In vivo direct molecular imaging of early tumorigenesis and malignant progression induced by transgenic expression of GFP-Met. Neoplasia. 2006;8:353-63.

73. Olwill SA, Joffroy C, Gille H, Vigna E, Matschiner G, Allersdorfer A, et al. A highly potent and specific MET therapeutic protein antagonist with both ligand-dependent and ligand-independent activity. Mol Cancer Ther. 2013; 12:2459-71.

74. van Scheltinga AG T, Lub-de Hooge MN, Hinner MJ, Verheijen RB, Allersdorfer A, Hulsmeyer $\mathrm{M}$, et al. In vivo visualization of MET tumor expression and anticalin biodistribution with the MET-specific anticalin 89Zr-PRS-110 PET tracer. J Nucl Med. 2014:55:665-71.

75. Mross K, Richly H, Fischer R, Scharr D, Buchert M, Stern A, et al. First-inhuman phase I study of PRS-050 (Angiocal), an Anticalin targeting and antagonizing VEGF-A, in patients with advanced solid tumors. PLoS One. 2013;8:e83232.

76. Wu C, Tang Z, Fan W, Zhu W, Wang C, Somoza E, et al. In vivo positron emission tomography (PET) imaging of mesenchymal-epithelial transition (MET) receptor. J Med Chem. 2010;53:139-46.

77. Pool M, van Dam GM, de Vries EG. Emerging opportunities for C-MET visualization in the clinic. J Nucl Med. 2016:57:663-4.

\section{Submit your manuscript to a SpringerOpen ${ }^{\circ}$ journal and benefit from:}

- Convenient online submission

- Rigorous peer review

- Immediate publication on acceptance

- Open access: articles freely available online

- High visibility within the field

Retaining the copyright to your article 